\title{
A Common-Fate Analysis of Pornography Acceptance, Use, and Sexual Satisfaction Among Heterosexual Married Couples
}

\author{
Cameron C. Brown \\ Kansas State University \\ Jason S. Carroll \\ Brigham Young University - Provo, jcarroll@byu.edu \\ Jeremy B. Yorgason \\ Brigham Young University - Provo \\ Dean M. Busby \\ Brigham Young University - Provo \\ Brian J. Willoughby

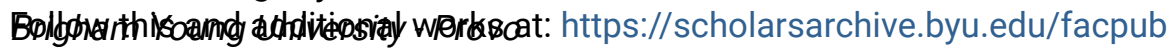 \\ Part of the Other Social and Behavioral Sciences Commons
}

See next page for additional authors

Original Publication Citation

Brown, C.C.*, Carroll, J. S., Yorgason, J. B., Busby, D. M., Willoughby, B. J., \& Larson, J. H. (2017).

A Common-Fate Analysis of Pornography Use, Acceptance, and Sexual Satisfaction Among Heterosexual Married Couples. Archives of Sexual Behavior, 46(2), 575-584.

\section{BYU ScholarsArchive Citation}

Brown, Cameron C.; Carroll, Jason S.; Yorgason, Jeremy B.; Busby, Dean M.; Willoughby, Brian J.; and Larson, Jeffrey H., "A Common-Fate Analysis of Pornography Acceptance, Use, and Sexual Satisfaction Among Heterosexual Married Couples" (2016). Faculty Publications. 4368.

https://scholarsarchive.byu.edu/facpub/4368

This Peer-Reviewed Article is brought to you for free and open access by BYU ScholarsArchive. It has been accepted for inclusion in Faculty Publications by an authorized administrator of BYU ScholarsArchive. For more information, please contact ellen_amatangelo@byu.edu. 
Authors

Cameron C. Brown, Jason S. Carroll, Jeremy B. Yorgason, Dean M. Busby, Brian J. Willoughby, and Jeffrey H. Larson 


\title{
A Common-Fate Analysis of Pornography Acceptance, Use, and Sexual Satisfaction Among Heterosexual Married Couples
}

\author{
Cameron C. Brown' ${ }^{1}$ (1) J Jason S. Carroll ${ }^{2} \cdot$ Jeremy B. Yorgason $^{2} \cdot$ Dean M. Busby $^{2} \cdot$ \\ Brian J. Willoughby ${ }^{2} \cdot$ Jeffry H. Larson $^{3}$
}

Received: 3 April 2015 / Revised: 2 November 2015 / Accepted: 29 February 2016/ Published online: 18 April 2016

(C) Springer Science+Business Media New York 2016

\begin{abstract}
Using matched, heterosexual couple data from the Relationship Evaluation Questionnaire (RELATE; $n=326$ couples), an adapted common-fate approach was used to examine both common and unique attributes of husbands' and wives' acceptance of pornography and sexual satisfaction as well as husbands' and wives' pornography use. It was expected that spouses' unique as well as shared variance of pornography acceptance would be significantly associated with husbands' and wives' levels of personal pornography use and that these use patterns would be significantly associated with husbands' and wives' unique as well as shared variance of sexual satisfaction. It was also expected that pornography use would significantly mediate the relationship between pornography acceptance and sexual satisfaction. Results indicated that the shared variance of pornography acceptance was positively associated with both spouses' pornography use and that spouses' pornography use was negatively associated with their own sexual satisfaction. Wives' pornography use was found to be positively associated with the couple's shared variance of sexual satisfaction, but pornography use did not significantly mediate the relationship between pornography acceptance and sexual satisfaction. These findings emphasize the complexity of pornography use in couple relationships and the importance of studying pornography
\end{abstract}

Cameron C. Brown

browncc@ksu.edu

1 Marriage and Family Therapy, School of Family Studies and Human Services, Kansas State University, 139 Campus Creek Complex, Campus Creek Road, Manhattan, KS 66506, USA

2 School of Family Life, Brigham Young University, Provo, UT, USA

3 Marriage and Family Therapy, School of Family Life, Brigham Young University, Provo, UT, USA acceptance and use as a coupling dynamic within marriages rather than just an individual behavior.

Keywords Couples $\cdot$ Marriage $\cdot$ Pornography $\cdot$ Sexuality . Sexual satisfaction

\section{Introduction}

As pornography has become more accessible and normative in modern culture, researchers have begun to examine the possible effects of pornography use on a variety of personal behaviors and relationship outcomes (Bridges \& Morokoff, 2011; Carroll et al., 2008; Maddox, Rhoades, \& Markman, 2009; Olmstead, Negash, Pasley, \& Fincham, 2013; Poulsen, Busby, \& Galovan, 2013; Yucel \& Gassanov, 2010). Despite a growing literature on pornography use and its relation to individual outcomes, very little research has been done on the pornography use within couple relationships. In recent years, studies have begun to shed some light on possible negative (Bridges, Bergner, \& Hesson-McInnis, 2003; Bridges \& Morokoff, 2011; Lambert, Negash, Stillman, \& Olmstead, 2012; Maddox et al., 2009; Poulsen et al., 2013; Stewart \& Szymanski, 2012; Yucel \& Gassanov, 2010) and positive (Daneback, Traeen, \& Mansson, 2008; Grov, Gillespie, Royce, \& Lever, 2011; Popovic, 2011) outcomes of pornography use for heterosexual couples. Despite these advances, more research is needed to more clearly understand to what extent each partner's pornography use associates with outcomes such as sexual satisfaction within their romantic relationship.

A possible explanation for the mixed findings in pornography studies to date is that scholars are typically assuming that the so-called "pornography use" is the same phenomenon for all heterosexual couples, despite that acceptance levels of pornography use may vary widely among users and their partners (Carroll et al., 2008). In other words, most studies simply use a measure of 
reported frequency of pornography use without probing deeper into other features of the relationship, such as acceptance levels of pornography. Symbolic interaction theory suggests that individuals and couples hold symbolic internal meanings that influence behaviors and their consequences (Blumer, 1986). This can be applied to pornography acceptance (meaning making) and pornography use (behavior). Using symbolic interaction theory as a guide post, the present study sought to further pornography research by examining pornography use within couple relationships and how it associates with broader patterns of sexual satisfaction in marriage. Specifically, this study used a matched couple dataset of heterosexual marriages to explore husband and wife pornography use, acceptance of pornography, and dimensions of sexual satisfaction.

\section{Understanding Pornography Within the Couple Context}

Despite the recent influx of studies examining pornography, current research continues to primarily focus on pornography use in terms of simple frequency of use which often ignores the relationship's context of differences in use patterns between partners and whether or not partners accept each other's use (see Manning, 2006). There have been some attempts in more recent studies to look beyond frequency of use due to the belief that different contexts surrounding pornography use may lead to different outcomes on an individual and couple level (Poulsen et al., 2013; Willoughby, Carroll, Busby, \& Brown, 2016). These developments are important, for these factors may more fully explain inconsistent and conflicting results in studies to date regarding couple outcomes, as well as offer a way for scholars to develop a fuller theoretical foundation to explain how pornography may influence different couples in different ways.

\section{Gender Differences}

To begin to understand pornography use within heterosexual relationships, it is important to contextualize couple patterns within one of the most consistent findings among pornography studies: gender differences. To date, pornography is predominantly used by men (Albright, 2008; Buzzell, 2005; Carroll et al., 2008; Cooper, Galbreath, \& Becker, 2004; Cooper, MorahanMartin, Mathy, \& Maheu, 2002; Emmers-Sommer, Hertlein, \& Kennedy, 2013; McKee, 2007; Stack, Wasserman, \& Kern, 2004), although some popular culture outlets suggest that pornography use is on the rise among women (Brennan, 2010; Carey, 2011). Carroll et al. (2008) found that close to $50 \%$ of men in their sample reported weekly or more pornography use while only $3.2 \%$ of women reported weekly or more use patterns. Other research depicted men doubling women's weekly average of online sexual use, $2.8 \mathrm{~h}$ per week contrasted to $1.4 \mathrm{~h}$ per week (Cooper et al., 2002). This consistent finding of gender differences suggests the need for further work examining couple dynamics surrounding pornography use within heterosexual couple relationships, particularly if these differences reflect acceptance differences between partners.

\section{Acceptance of Pornography}

While pornography use has become a more acceptable and normative form of sexual expression by men and women, what happens to these individuals and their couple dynamics when they enter relationships? In a recent qualitative study, Olmstead et al. (2013) suggested varying ways heterosexual individuals in couple relationships approach pornography use within the relationship. Although many participants believed that pornography use was not appropriate in romantic relationships, some participants believed pornography use was appropriate and reported that they saw it as a relationship enhancement tool. Although acceptance of pornography use existed in these particular relationships, it is worth noting that it was primarily based on certain conditions, such as pornography should be viewed together or that the frequency, duration, and content should be within an appropriate limit.

Another study found that heterosexual couples who had greater pornography use differences, where one partner used pornography much more than the other, were associated with less relationship satisfaction, less relationship stability, less positive communication, and more relational aggression (Willoughby et al., 2016). These associations were found to be moderated by acceptance levels of each partner in the relationship, with greater acceptance weakening the association of pornography use with couple outcomes. This study suggests the significant role that acceptance plays in the association between pornography use patterns and relational outcomes.

\section{Sexual Satisfaction}

Previous literature suggests associations between pornography use and sexuality (Grov et al., 2011; Maddox et al., 2009; Yucel $\&$ Gassanov, 2010), and thus when analyzing pornography use within the couple context, it is important to consider a couple's sexual dynamics as well. Sexual desire and satisfaction play an important role in the development of romantic relationships and is an integral constituent of marital quality (Regan \& Atkins, 2006; Yabiku \& Gager, 2009). Sexual intimacy is seen as a powerful bonding and attachment-strengthening experience within many monogamous, romantic relationships (Zitzman \& Butler, 2009).

Pornography research exploring links with sexual behaviors and relationships presents mixed findings. Some research suggests sexual satisfaction being negatively associated with pornography use for heterosexual couples (Maddox et al., 2009; Yucel \& Gassanov, 2010), while another study suggests that sexual education, improved body image, and comfort level with sex are positively associated with pornography use (Watson \& 
Smith, 2012). These mixed findings highlight the necessity for further research on specific ways that pornography use influences sexual satisfaction in committed couple relationships.

\section{The Present Study}

Not only has pornography research to date not considered the couple context thoroughly enough, there is a significant void of theory addressing how pornography use may relate to couple dynamics. As noted earlier, the picture emerging from current studies is that there are frequently differing behaviors and beliefs between husbands and wives related to pornography (Albright, 2008; Bridges \& Morokoff, 2011; Grov et al., 2011). These findings suggest that the meaning or interpretation of pornography matters as much for couples as do the use patterns of partners. In particular, partner's acceptance levels of pornography set the context for whether pornography use is taking place in agreement with or in violation of relationship boundaries or sexual beliefs and expectations.

The present study was guided by symbolic interaction theory (Blumer, 1986), which suggests that internal symbolic meaning will influence behavioral decisions and their consequences. Symbolic interactionism focuses on the shared meaning created from individuals' interactions with each other (Blumer, 1986). As shared meaning making increases within a couple's relationship, intimacy and closeness are often increased (LaRossa \& Reitzes, 1993); however, when partners do not have shared meaning, they experience less satisfaction and connection. Zitzman and Butler (2009) suggested that differences in meaning related to pornography are highly symbolic for many monogamous couples and that these differences in meaning can have impact on the bond between partners.

Acknowledging the importance of acceptance levels and the potential symbolism of pornography connects with Schnarch's (1991) sexual crucible theory, which emphasizes the human capacity for intimacy and the emotional meanings that inevitably accompany sexual experience. This theory emphasizes that sexual response is determined by two components: physical stimulation and psychological stimulation. Physical stimulation is the amount of "external stimulation" experienced during sex and is the function of the quality and quantity of physical touch and the capacity of the body to experience it. Psychological stimulation is the amount of "internal stimulation" experienced during sex and refers to the emotions and thoughts partners have during sex and is influenced by partners' attitudes and approaches to sexuality as well as the quality of the overall relationship surrounding a particular sexual experience. When pornography use infringes on partners' sexual expectations or beliefs, it may be viewed symbolically as a relationship violation, thus disrupting psychological stimulation in the couple's shared sexual relationship. If this disruption becomes prolonged or intense enough, it may diminish overall sexual satisfaction for the offended partner, and in time, create a sexual pattern that is less satisfying to the using partner.

To best utilize the matched couple dataset of the present study, a modified common-fate analysis was performed. Common-fate analysis is an alternative approach to an Actor/Partner Interdependence Model (APIM; Kenny \& Cook, 1999) and was first introduced by Kenny and La Voie (1985). This approach to dyadic data has the basic assumption that there are variables that affect both partners in the relationship and that this effect may be similar (shared) and different (unique) for each partner (Ledermann \& Kenny, 2012). For example, if a husband scores higher on a variable, such as pornography acceptance than his wife, that uniqueness is noted within the model and has the ability to predict reports of sexual satisfaction. This approach assists in better understanding what is occurring within the dyad as well as between dyads (Ledermann \& Kenny, 2012).

Building upon a symbolic interaction perspective of the importance of meaning making related to pornography and existing studies on pornography, three hypotheses are posed for how pornography use and acceptance relates to heterosexual couple relationships, particularly the level of sexual satisfaction. These hypotheses seek to add further clarity in the pornography literature by investigating acceptance and use of pornography through a dyadic lens and how it relates to a couple's sexual satisfaction. Tobest evaluate these hypotheses, a mediating model is proposed.

Hypothesis 1 Husbands' and wives' personal pornography use are expected to significantly and positively be associated with husbands' and wives' unique, as well as shared, variance on pornography acceptance.

Hypothesis 2 Husbands' and wives' unique, as well as shared, variance on sexual satisfaction is expected to significantly and negatively be associated with husbands' and wives' individual pornography use.

Hypothesis 3 Pornography use is expected to significantly mediate the relationship between pornography acceptance and sexual satisfaction.

\section{Method}

\section{Participants}

The sample consisted of 335 heterosexual, married matched couples who completed the Relationship Evaluation Questionnaire (RELATE; Busby, Holman, \& Taniguchi, 2001). This tool was developed in 1980 and currently maintained by the RELATE Institute, a multidisciplinary team of social researchers, educators, and helping professionals seeking to understand the complexities of romantic relationships. It assesses participants in areas of individual, couple, familial, and cultural contexts with 
ambitions to assist couples by offering insight into their relationship (Busby et al., 2001). The participants in this study were predominantly Caucasian $(74.74 \%$ ) with $8.37 \%$ being African American, $5.68 \%$ Latino, $4.48 \%$ Asian, $3.44 \%$ biracial, $2.24 \%$ other, and $1.05 \%$ Native American. The mean age for husbands was $38.23(S D=10.43)$ years and $36.16(S D=9.88)$ years for wives. This sample was also well educated with $74.63 \%$ of the participants having received their associate's degree or a higher collegiate degree. Approximately $38 \%$ of the sample was married to their current partner less than 2 years, $40 \%$ reported being married 3-15 years, and $19.2 \%$ reported being married 16 years or longer. When participants were inquired about their religion, $34.62 \%$ reported being Protestant, $24.78 \%$ having no religious affiliation, $19.4 \%$ Catholic, 3.73\% Jewish, 3.13\% Latter-day Saint, $1.64 \%$ Buddhist, $<1 \%$ Hindu, $<1 \%$ Taoism, and $10.9 \%$ "other."

\section{Procedure}

Participants completed the RELATE questionnaire between 2011 and 2013 after being introduced to the tool through various means. The majority reported being introduced to the questionnaire through a therapist (31.34\%), instructor (25.82\%), or family member $(21.04 \%)$. All participants completed an appropriate consent form before completing the RELATE questionnaire and all data collection procedures were approved by the Institutional Review Board at Brigham Young University.

\section{Measures}

RELATE is a 300-item questionnaire designed to evaluate the relationship of individuals in dating, engaged, or married relationships. The questionnaire examines several different areas of individual, cultural, family (of origin), and couple functioning. Busby et al. (2001) offer more information regarding the RELATE questionnaire including a detailed description of its reliability and validity.

\section{Pornography Acceptance}

Pornography acceptance was assessed using items cited in previous research studies (Carroll et al., 2008; Willoughby et al., 2016). Each partner responded to six items assessing one's acceptance of pornography use individually on an overall Likerttype scale $(1=$ strongly disagree $; 5=$ strongly agree $)$. This variable was created by averaging the six item scale separately for husbands $(\alpha=.90)$ and for wives $(\alpha=.90)$. Example acceptance items include: "Viewing pornography is an acceptable way for single adults to express their sexuality," "Pornography is an acceptable way for couples to 'spice up' their love life," and "Pornography Acceptance is a form of marital infidelity" (reverse coded). The mean value for the pornography acceptance scale for husbands was $3.09(S D=1.03)$ and for wives was 2.75
$(S D=1.02)$. When modeled as a latent variable to illustrate husband and wife shared pornography acceptance as well as husband and wife unique acceptance, the factor loadings were statistically significant $(p<.001)$ for each partner, with standardized estimates of .80 (husbands) and .84 (wives).

\section{Pornography Use}

Pornography use was assessed by one item asked of each participant: "During the last 12 months, on how many days did you view or read pornography (i.e., movies, magazines, internet sites, adult romance novels)?" Response options were on a 6-point, Likert-type scale ranging from 0 (none) to 5 (almost every day). Two variables were formed with this measure: the husband report of pornography use and the wife report of pornography use. The mean pornography use for husbands was $1.52(S D=1.38)$ and for wives was $.54(S D=.81)$.

\section{Sexual Satisfaction}

Sexual satisfaction was measured by a six-item subscale of the Golombok Rust Inventory of Sexual Satisfaction (GRISS; Rust \& Golombok, 1986). Each response ranged from 1 (never) to 5 (almost always) on a Likert-type scale. This scale has appropriate reliability and validity. These six items focused on domains of variety, love/affection, time, and frequency, and consisted of questions such as, "Are you dissatisfied with the amount of variety in your sex life with your partner?" (reverse coded) and "Do you have sexual intercourse as often as you would like?" Similar to the previous variable, this variable was created by averaging the six-item scale for the husband $(\alpha=.87)$ and then for the wife $(\alpha=.83)$. The mean value for the Sexual Satisfaction scale for husbands was $3.29(S D=.90)$ and for wives was $3.42(S D=$ .89). A latent variable was created to estimate husband and wife shared sexual satisfaction as well as husband and wife unique sexual satisfaction. Factor loadings were statistically significant $(p<.001)$ for each partner with standardized estimates of .79 for husbands and .76 for wives.

\section{Controls}

As outlined in previous literature, there are numerous variables that need to be considered when analyzing pornography use and couple sexuality. Factors such as religiosity (Lichter \& Carmalt, 2009; Nelson, Padilla-Walker, \& Carroll, 2010), length of relationship (Greeley, 1991), and socioeconomic factors such as education (Owen, Rhoades, Stanley, \& Fincham, 2010) are important to consider when evaluating sexuality and pornography. These controls have been applied to the current model to best address the research questions.

Religiosity. Religiosity was assessed using one item: "How often do you attend religious services?" where participants answered 1 (Never) to 5 (Weekly). Husband and wife scores 
were then averaged together to create a couple religiosity score. The mean of religiosity for husbands was $2.78(S D=1.50)$ and for wives was $2.89(S D=1.54)$.

Length of Relationship. Length of relationship was assessed using one item: "How long have you and your partner been married?" where participants answered on a scale of 1 to $11(1=0$ to 3 months to $11=$ More than 40 years). Only the wives' report was used in this control. The mean value was $1.51(S D=1.37)$.

Education. Education was assessed using one item: "How much education have you completed?" where participants answered on a scale of 1-9 (1= Less than high school to $9=$ Graduate or professional degree, completed). Both husbands' and wives' reports were used as a control. The mean for education for husbands was $7.11(S D=1.72)$ and for wives was 6.70 $(S D=2.16)$.

\section{Data Analysis}

To examine the associations between husband and wife sexual satisfaction, pornography use, and pornography acceptance, structural equation modeling (SEM) was used within Mplus software (Version 7; Muthén \& Muthén, 1998-2012). Husband and wife pornography use were modeled as observed variables, whereas pornography acceptance and sexual satisfaction were modeled as latent variables. The mediation model estimated consisted of pornography acceptance $\rightarrow$ pornography use (husband and wife) $\rightarrow$ sexual satisfaction.

To answer the research questions and examine the unique and shared values of the distinguishable dyad dataset, an adapted common-fate multilevel SEM model was used. This commonfate analysis was modified from the model presented in Peugh, DiLillo, and Panuzio (2013), where husband and wife observed variables are indicators of a common-fate latent variable that represent shared, between couple variation. In the current analysis, the common-fate variables represent the correlation between husband and wife items regarding their acceptance of pornography and sexual satisfaction. With these same variables, distinct residual variance latent variables for husbands as well as wives were used to characterize within-person, unique variation that was not captured by the common-fate variable. The factor loadings for each of the three unique latent variables were fixed to one for unity (Griffin \& Gonzalez, 1995). This model illustrated excellent model fit $\left(\chi^{2}=10.88[d f=9], p>.05 ;\right.$ RMSEA $=$ $.03 ; \mathrm{CFI}=1.00 ; \mathrm{SRMR}=.02)$ (see Hu \& Bentler, 1999). As previous literature has illustrated with mediating models (MacKinnon, 2008), a bootstrap procedure was applied to the analysis to estimate appropriate standard errors for the indirect effects (5000 bootstrap draws used).

The common-fate variables of pornography acceptance and sexual satisfaction were preferred to an APIM (Kenny \& Cook, 1999) because the husband and wife measures for each of the common-fate variables were highly correlated (pornography acceptance: $r=.67$; sexual satisfaction: $r=.56)$. High correlations between husband and wife reports indicated substantial amount of shared variation and thus expected to yield reliable commonfate estimates (Ledermann \& Kenny, 2012). If a traditional APIM approach was modeled with these variables, collinearity between husband and wife variables would be present due to non-independence and could ultimately alter the findings. A commonfate latent variable was not created for pornography use because of the lower correlation between husband and wife reports ( $r=$ .29), illustrating appropriateness for a traditional actor/partner use. Further, scholars recommend consideration of a commonfate analysis for specific variables highlighting relationship dynamics such as relationship satisfaction in dyadic data (Ledermann \& Macho, 2014). Using the present common-fate model, we avoid analysis concerns such as collinearity but also impose a limitation because the common-fate approach does not permit the crossing of actor/partner paths such as found in a traditional APIM. For example, this specific model does not allow wives' unique pornography acceptance to predict husbands' sexual satisfaction. Lastly, due to the complexity of the model, nine cases that contained missing data were removed from the analysis, limiting our sample size to 326 dyads (Fig. 1).

\section{Results}

Preliminary analysis of bivariate correlations of husbands' and wives' pornography use, pornography acceptance, and sexual satisfaction indicate several significant results. Husbands' pornography use was positively correlated with their pornography acceptance $(r[332]=.42, p<.01)$, sexual satisfaction $(r[332]=-.13, p<.05)$, wives' pornography use $(r[332]=$ $.29, p<.01)$, and wives' pornography acceptance $(r[331]=$ $.41, p<.01)$. Husbands' sexual satisfaction was significantly correlated with wives' sexual satisfaction $(r[329]=.56, p<.01)$ and pornography use $(r[332]=.14, p<.05)$. Husbands' pornography acceptance was significantly correlated with wives' pornography acceptance $(r[332]=.67, p<.01)$ and pornography use $(r[332]=.27, p<.01)$. Wives' pornography use was significantly correlated with their pornography acceptance $(r[331]=.41, p<.01)$. In summary, the main variables in the study were correlated in expected directions and to expected strengths.

\section{Hypothesis 1}

As anticipated with our first hypothesis, husbands' and wives' pornography acceptance reports were linked with their pornography use. Specifically, in partial support of what was expected, the common-fate portion of pornography acceptance was associated with both husbands' $(B=.89, p<.001 ; \beta=.52)$ and wives' $(B=.56, p<.001 ; \beta=.54)$ pornography use. 
Fig. 1 Unstandardized (standardized) coefficients from an adapted common-fate model of husbands' and wives' pornography acceptance and use predicting sexual satisfaction as controlled by education, religiosity, and length of relationship $(n=326)$. * $p<.05$; $* * p<.01 ; * * * p<.001$. Model fit: $\chi^{2}=11.97(d f=9), p>.05$; $\mathrm{RMSEA}=.03 ; \mathrm{CFI}=1.00$; $\mathrm{SRMR}=.02$

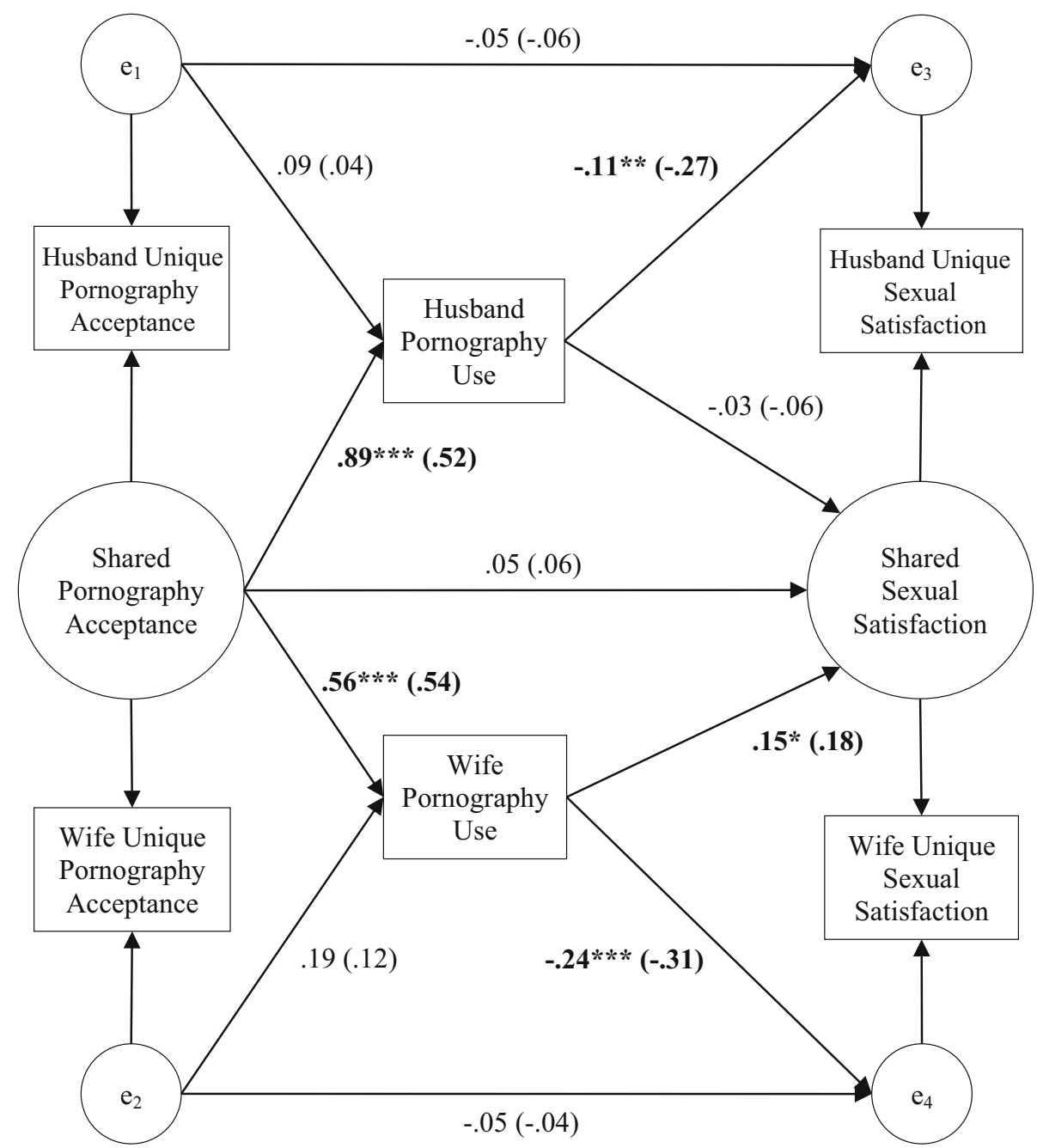

\section{Hypothesis 2}

Significant findings partially supported the second hypothesis that husbands' and wives' individual pornography use would negatively associate with sexual satisfaction. Husbands' pornography use was negatively associated with their unique sexual satisfaction $(B=-.11, p<.01 ; \beta=-.27)$. Wives' pornography use was also negatively associated with their unique sexual satisfaction $(B=-.24, p<.001 ; \beta=-.31)$, yet positively associated with the shared or common portion of sexual satisfaction $(B=.15, p<.05 ; \beta=.16)$.

\section{Hypothesis 3}

Findings did not support our third hypothesis that husband and wife pornography use would mediate links between pornography acceptance and sexual satisfaction. Although there were some significant paths between pornography acceptance and pornography use, and between pornography use and sexual satisfaction, when bootstrapping to adjust standard error was used, no significant indirect effects, unique or shared, were found.
Specifically, results showed that indirect associations did not exist between husbands' and wives' unique pornography acceptance and their sexual satisfaction through pornography use of husbands' $(B=-.002, p=.93,95 \% \mathrm{CI}[-.05, .05] ; \beta=-.002)$ or wives' $(B=-.05, p=.11,95 \% \mathrm{CI}[-.12, .01] ; \beta=-.04)$. Furthermore, neither indirect associations between shared pornography acceptance, pornography use, and shared sexual satisfaction for husbands' $(B=-.04, p=.48,95 \% \mathrm{CI}[-.18$, $.05] ; \beta=-.05)$ or wives' $(B=.08, p=.09,95 \% \mathrm{CI}[.01, .19]$; $\beta=.09$ ) was significant after bootstrapping.

\section{Discussion}

The results of this study strengthen the argument that pornography is more than simply an individual behavior, but rather is best seen as a relationship phenomenon. As noted previously, minimal research has been done to date that examines pornography within the couple context and even fewer studies regarding pornography have been published utilizing matched couple data (Bridges \& Morokoff, 2011; Daneback et al., 2008). 
Furthermore, while there are multiple approaches to analyzing dyadic data, common-fate modeling offers a particularly valuable tool for examining what is occurring within couple relationships regarding pornography use and sexual outcomes. It allows us to see how spousal pornography use is specifically associated with each partner (unique) as well as the couple (shared). This analysis approach was particularly well suited for the matched couple data utilized in this study to avoid collinearity concerns. Further, dyadic variables, such as pornography acceptance and sexual satisfaction, are fitting for commonfate modeling because they measure aspects of the relationship and beliefs where couples may share common ground (Ledermann \& Kenny, 2012).

Some insights can be gained from the initial process of building the common-fate model analyzed in this study. For example, one of the first items noted while building this common-fate model was the differences in pornography use between husbands and wives. As highlighted above, when attempting to create a common-fate latent variable of pornography use for both spouses, it was concluded that their pornography use patterns were too different to load together. This difference in use between husbands and wives was in line with previous pornography literature pointing to considerable differences between men and women's pornography use patterns (Bridges \& Morokoff, 2011; Carroll et al., 2008; Cooper et al., 2002; Poulsen et al., 2013). However, this study took this finding a step further by confirming that these differences continue after marriage for many couples.

The specifics of the analysis also offer some insights surrounding pornography use within couple relationships. Specifically, wives' and husbands' pornography use was strongly and positively associated with their shared pornography acceptance. Also, husbands' unique sexual satisfaction was negatively related to their pornography use and wives' unique sexual satisfaction was negatively related to their pornography use as well. Wives' pornography use, however, was positively related to the couple's shared level of sexual satisfaction. Also, the present model illustrated that husbands' or wives' individual pornography use did not mediate the relationship between husbands' and wives' unique or shared pornography acceptance and unique or shared sexual satisfaction. These findings were evaluated after controlling for education, relationship length, and religiosity.

The present findings support existing studies which suggest that men's and women's pornography use patterns generally differ not only with use, but also with outcomes both individually and relationally (Bridges \& Morokoff, 2011; Daneback et al., 2008; Grov et al., 2011; Yucel \& Gassanov, 2010). The negative relationship between husbands' pornography use and unique sexual satisfaction in marriage could be explained by prior research indicating that many individuals view pornography as a personal, rather than relational, sexual experience (Cooper et al., 2004). Some have labeled this type of pornography use as "auto-erotic sexuality" (Hald, Seaman, \& Linz,
2014). In this regard, pornography use in marriage may be a trade-off between a husband's auto-erotic experiences and his relational sexual satisfaction with his wife. Husbands' pornography use may contribute to poorer individual sexual satisfaction because it may become a sexual reference point or comparison base to real sexual experiences.

A surprising finding from this study was that under the second hypothesis, there were contradictions in that wives' pornography use was positively associated with the couple's shared level of sexual satisfaction, but was negatively associated with wives' unique sexual satisfaction. Recent literature supports the belief that pornography use by women may have more of a positive influence on a couple's sexual relationship because it may represent more of an openness on the part of the wife to try new sexual behaviors and foster an overall more erotic climate in the relationship (Bridges \& Morokoff, 2011; Grov et al., 2011). Such an approach to marital sexuality may be more in harmony with the sexual expectations of husbands, particularly those who view pornography. Other studies also illustrate that women who use pornography do so primarily to enhance their sexual relationships rather than to engage in auto-erotic sexual experiences (Cooper et al., 2004; Hald et al., 2014). The current study supported that belief within the couple's shared sexual satisfaction, but not within wives' unique sexual satisfaction. This finding may best be explained through symbolic interaction theory, which suggests that meaning making not only influences behaviors, but may also influence the perceived consequences of those behaviors (Blumer, 1986). Could this finding be explained by a wife attempting to satisfy her husband by applying in her marriage what she has picked up from pornographic depictions of sex, but also finding such behaviors unauthentic or less satisfying? Further, as previous literature has suggested, it may simply be wives' feeling pressure or unrealistic expectations that pornography may instill in its users (Grov et al., 2011). The measures in the present study did not allow for a full investigation of wives' meaning making that may lead to this contradiction between shared and unique satisfaction patterns, but this peculiar finding needs deeper investigation.

Mediation analysis considering pornography acceptance to pornography use to sexual satisfaction also sheds some light on how couples perceive pornography. Although higher pornography use is associated with higher pornography acceptance, mediation analysis illustrated that pornography use did not mediate the relationship between acceptance and sexual satisfaction. Further, direct effects illustrated no significant association between pornography acceptance and sexual satisfaction. This finding suggests that other factors surrounding pornography use are influencing sexual satisfaction and that pornography is not simply a consensus issue in a couple's relationship. Although surprising, this finding aligns with previous literature that pornography, despite context, can still have negative relational outcomes (Yucel \& Gassanov, 2010). 


\section{Limitations}

Although this study furthers previous literature surrounding pornography use within romantic relationships, there were some limitations that need to be considered. First, by incorporating a common-fate analysis into the current model, a more detailed look into relational dynamics surrounding pornography use was acquired by avoiding collinearity, but was limited to the extent of detail that the analysis examined. Common-fate analysis does not permit cross-gender predictions among the unique variables of pornography acceptance and sexual satisfaction. Gaining further insight into how an individual's attitudes or actions concerning pornography use may associate with their partner's attitudes or actions would offer valuable results to further expand the relational pornography literature.

Further, previous literature has shown that some couples use pornography to "spice" up their sex life (Daneback et al., 2008; Maddox et al., 2009; Olmstead et al., 2013). This model does not consider whether the reported pornography use was viewed together as a couple or alone. Also, considering the recruitment strategy and the medium of the questionnaire, the RELATE questionnaire likely oversampled younger couples and couples with higher socioeconomic status than more nationally representative samples. Although pornography use was prevalent in this sample, lower frequency of use was reported relative to other studies (see Carroll et al., 2008; Emmers-Sommer et al., 2013). These reports of low use limit the extent of evaluating the complete nature of pornography use within couples.

Other limitations include that this sample only examined heterosexual married dyads and did not consider other forms of sexual relationships. It is also worth noting that although not a clinical sample, many couples were referred to the RELATE questionnaire by a therapist and thus may have reported more distressed reports of their relational dynamics. Lastly, the measures used in this study did not take into consideration the type of content of the pornography used or the duration of use per viewing period. This information would allow a deeper understanding of what it is about pornography that plays a role in individual outcomes and relational dynamics.

\section{Research Implications and Future Direction}

The present study's findings uncover important issues for researchers. First, this study supports the systemic perspective that pornography is a coupling dynamic that should be considered when evaluating aspects of a couple's sexuality. This study introduced a significant relationship between sexual satisfaction and pornography use. For many couples, sexual satisfaction is closely correlated with relationship satisfaction (Byers, 2005); thus, it may be of value for future relationship researchers to not only consider sexual satisfaction but also incorporate pornography use patterns. Lastly, results from this study illustrate that husbands' and wives' pornography use patterns associate differently with sexual satisfaction. Researchers should look for and seek to understand these differences between partners concerning their own use of pornography and its relationship with their own sexuality.

This study continues to open the door for further understanding of pornography practices within a relational context. Future research of pornography use needs to consider specific methodologies in the gathering and analyzing of data that will allow cross-partner effects of attitudes and partners, which is lacking in the present study. Also, future research needs to consider pornography patterns along the coupling continuum from casual dating to more committed relationships to evaluate how these couples are incorporating or reacting to the existence of pornography within their relationship. Optimally, longitudinal approaches would offer valuable insight on if/how pornography use may transform as a relationship progresses. Further, this approach would allow a clearer picture of predictive individual and relational outcomes rather than statistical associations.

Additional academic consideration is also needed in evaluating how couples negotiate individual and/or couple pornography use and how this use may contribute to their sexual scripts (see Simon \& Gagnon, 1986) and sexual patterns. With the current study illustrating associations of pornography use with sexual satisfaction, future research needs to further understand how pornography use is associated with sexual satisfaction. To offer a greater detail of pornography use within the relational context, future work incorporating other relationship measures such as well-being, stability, and conflict would be valuable. Similar work needs to also be done among varying ages, SES, and cultures to build upon our basic understanding of pornography use among varying populations. Further, this study narrowly focuses on the sexual relationship of heterosexual, monogamous marital dyads and excludes other forms of sexual relationships. The heterosexual marital dyad is only one form of romantic relationship, among many, and thus further evaluation of the varying romantic relationships including dating, polyamorous, samesex, etc. is required to broaden our understanding of pornography use within relationships.

In conclusion, this study builds upon previous literature depicting the importance of not only seeing pornography use as an individual factor or a personal choice, but rather a dynamic that exists within heterosexual romantic relationships, where researchers should consider it systemically.

\section{References}

Albright, J. M. (2008). Sex in America online: An exploration of sex, marital status, and sexual identity in internet sex seeking and its impacts. Journal of Sex Research, 45, 175-186.

Blumer, H. (1986). Symbolic interactionism: Perspective and method. Berkeley: University of California Press.

Brennan, R. (2010, June 7). Getting to know you: Let's talk about porn... Glamour. Retrieved from http://www.glamour.com/sex-love-life/ blogs/smitten/2010/06/getting-to-know-you-lets-talk-3.html. 
Bridges, A. J., Bergner, R. M., \& Hesson-McInnis, M. (2003). Romantic partners' use of pornography: Its significance for women. Journal of Sex and Marital Therapy, 29, 1-14.

Bridges, A. J., \& Morokoff, P. J. (2011). Sexual media use and relational satisfaction in heterosexual couples. Personal Relationships, 18, 562-585.

Busby, D. M., Holman, T. B., \& Taniguchi, N. (2001). RELATE: Relationship evaluation of the individual, family, cultural, and couple contexts. Family Relations, 50, 308-316.

Buzzell, T. (2005). Demographic characteristics of persons using pornography in three technological contexts. Sexuality and Culture, 9, 2848.

Byers, E. (2005). Relationship satisfaction and sexual satisfaction: A longitudinal study of individuals in long-term relationships. Journal of Sex Research, 42, 113-118.

Carey, T. (2011, April 7). Why more and more women are using pornography. The Guardian. Retrieved from http://www.theguardian.com/culture/ 2011/apr/07/women-addicted-internet-pornography.

Carroll, J. S., Padilla-Walker, L. M., Nelson, L. J., Olson, C. D., Barry, C., \& Madsen, S. D. (2008). Generation XXX: Pornography acceptance and use among emerging adults. Journal of Adolescent Research, 23, $6-30$.

Cooper, A., Galbreath, N., \& Becker, M. A. (2004). Sex on the internet: Furthering our understanding of men with online sexual problems. Psychology of Addictive Behaviors, 18, 223-230.

Cooper, A., Morahan-Martin, J., Mathy, R. M., \& Maheu, M. (2002). Toward an increased understanding of user demographics in online sexual activities. Journal of Sex and Marital Therapy, 28, 105-129.

Daneback, K., Traeen, B., \& Mansson, S. A. (2008). Use of pornography in a random sample of Norwegian heterosexual couples. Archives of Sexual Behavior, 38, 746-753.

Emmers-Sommer, T., Hertlein, K., \& Kennedy, A. (2013). Pornography use and attitudes: An examination of relational and sexual openness variables between and within gender. Marriage \& Family Review, 49, 349-365.

Greeley, A. M. (1991). Faithful attraction: Discovering intimacy, love, and fidelity in American marriage. New York: Doherty.

Griffin, D., \& Gonzalez, R. (1995). Correlational analysis of dyad-level data in the exchangeable case. Psychological Bulletin, 118, 430-439.

Grov, C., Gillespie, B., Royce, T., \& Lever, J. (2011). Perceived consequences of casual online sexual activities on heterosexual relationships: A U. S. online survey. Archives of Sexual Behavior, 40, 429-439.

Hald, G. M., Seaman, C., \& Linz, D. (2014). Sexuality and pornography. In D. L. Tolman, L. M. Diamond, J. A. Bauermeister, W. H. George, J. G. Pfaus, \& L. Ward (Eds.), APA handbook of sexuality and psychology (Vol. 2, pp. 3-35). Washington, DC: American Psychological Association.

Hu, L., \& Bentler, P. M. (1999). Cutoff criteria for fit indexes in covariance structure analysis: Conventional criteria versus new alternatives. Structural Equation Modeling, 6, 1-55.

Kenny, D. A., \& Cook, W. L. (1999). Partner effects in relationship research: Conceptual issues, analytic difficulties, and illustrations. Personal Relationships, 6, 433-448.

Kenny, D. A., \& La Voie, L. (1985). Separating individual and group effects. Journal of Personality and Social Psychology, 48, 339-348.

Lambert, N. M., Negash, S., Stillman, T. F., \& Olmstead, S. B. (2012). A love that doesn't last: Pornography consumption and weakened commitment to one's romantic partner. Journal of Social and Clinical Psychology, 31, 410-438.

LaRossa, R., \& Reitzes, D. C. (1993). Symbolic interactionism and family studies. In P. G. Boss, W. J. Doherty, R. LaRossa, W. R. Schumm, \& S. K. Steinmetz (Eds.), Sourcebook of family theories and methods (pp. 135-166). New York: Plenum Press.
Ledermann, T., \& Kenny, D. A. (2012). The common fate model for dyadic data: Variations of a theoretically important but underutilized model. Journal of Family Psychology, 26, 140-148.

Ledermann, T., \& Macho, S. (2014). Analyzing change at the dyadic level: The common fate growth model. Journal of Family Psychology, 28, 204-213.

Lichter, D. T., \& Carmalt, J. H. (2009). Religion and marital quality among low-income couples. Social Science Research, 38, 168-187.

MacKinnon, D. P. (2008). Introduction to statistical mediation analysis. New York: Lawrence Erlbaum Associates.

Maddox, A. M., Rhoades, G. K., \& Markman, H. J. (2009). Viewing sexually-explicit materials alone or together: Associations with relationship quality. Archives of Sexual Behavior, 40, 441-448.

Manning, J. C. (2006). The impact of Internet pornography on marriage and the family: A review of the research. Sexual Addiction \& Compulsivity, 13, 131-165.

McKee, A. (2007). The relationship between attitudes towards women, consumption of pornography, and other demographic variables in a survey of 1,023 consumers of pornography. International Journal of Sexual Health, 19, 31-45.

Muthén, L. K., \& Muthén, B. O. (1998-2012). Mplus user's guide (7th ed). Los Angeles: Muthén \& Muthén.

Nelson, L. J., Padilla-Walker, L. M., \& Carroll, J. S. (2010). "I believe it is wrong but I still do it": A comparison of religious young men who do versus do not use pornography. Psychology of Religion and Spirituality, 2, 136-147.

Olmstead, S. B., Negash, S., Pasley, K., \& Fincham, F. D. (2013). Emerging adults' expectations for pornography use in the context of future committed romantic relationships: A qualitative study. Archives of Sexual Behavior, 42, 625-635.

Owen, J. J., Rhoades, G. K., Stanley, S. M., \& Fincham, F. D. (2010). "Hooking up" among college students: Demographic and psychosocial correlates. Archives of Sexual Behavior, 39, 653-663.

Peugh, J. L., DiLillo, D., \& Panuzio, J. (2013). Analyzing mixed-dyadic data using structural equation modeling. Structural Equation Modeling, 20, 314-337.

Popovic, M. (2011). Pornography use and closeness with others in men. Archives of Sexual Behavior, 40, 449-456.

Poulsen, F. O., Busby, D. M., \& Galovan, A. M. (2013). Pornography use: Who uses it and how it is associated with couple outcomes. Journal of Sex Research, 50, 72-83.

Regan, P. C., \& Atkins, L. (2006). Sex differences and similarities in frequency and intensity of sexual desire. Social Behavior and Personality, 34, 95-102.

Rust, J., \& Golombok, S. (1986). The GRISS: A psychometric instrument for the assessment of sexual dysfunction. Archives of Sexual Behavior, $15,157-165$.

Schnarch, D. M.(1991). Constructing the sexual crucible: An integration of sexual and marital therapy. New York: W. W. Norton \& Company.

Simon, W., \& Gagnon, J. H. (1986). Sexual scripts: Permanence and change. Archives of Sexual Behavior, 15, 97-120.

Stack, S., Wasserman, I., \& Kern, R. (2004). Adult social bonds and use of internet pornography. Social Science Quarterly, 85, 75-88.

Stewart, D. N., \& Szymanski, D. M. (2012). Young adult women's reports of their male romantic partner's pornography use as a correlate of their self-esteem, relationship quality, and sexual satisfaction. Sex Roles, $67,257-271$.

Watson, M., \& Smith, R. D. (2012). Positive porn: Educational, medical, and clinical uses. American Journal of Sexuality Education, 7, 122 145.

Willoughby, B. J., Carroll, J. S., Busby, D. M., \& Brown, C. C. (2016). Differences in pornography use among couples: Associations with satisfaction, stability, and relationship processes. Archives of Sexual Behavior, 45, 145-158. 
Yabiku, S. T., \& Gager, C. T. (2009). Sexual frequency and the stability of marital and cohabiting unions. Journal of Marriage and Family, 71, 983-1000.

Yucel, D., \& Gassanov, M. A. (2010). Exploring actor and partner correlates of sexual satisfaction among married couples. Social Science Research, $39,725-738$.
Zitzman, S. T., \& Butler, M. H. (2009). Wives' experience of husbands' pornography use and concomitant deception as an attachment threat in the adult pair-bond relationship. Sexual Addiction \& Compulsivity, 16, 210-240. 